\title{
Historia del reporterismo español. Estudio de caso de Miguel de la Quadra-Salcedo bajo la perspectiva digital
}

\author{
Jesús SEgarRA-SAAVEDRA \\ Universidad de Alicante \\ jesus.segarra@ua.es \\ Patricia PÁRAMO-GALDÓN \\ Diario Información \\ pparamo@epi.es
}

Recibido: 22 de junio de 2016

Aceptado: 8 de septiembre de 2016

\section{Resumen}

El reporterismo en España cuenta con una profusa labor periodística y numerosos profesionales desplazados hasta los lugares donde surgen los hechos y desde los que son narrados. En un contexto de difusión democratizada, digital, ubicua, social y multipantalla, resulta necesario acercarse a la historia del periodismo de reportero en nuestro país, así como conocer la labor realizada para ponerla en valor. El presente artículo estudia la figura de Miguel de la Quadra-Salcedo y la digitalización de su obra periodística llevada a cabo por TVE. Así mismo, rastrea su presencia en las principales redes y plataformas sociales justo antes y después de su fallecimiento.

Palabras clave: Historia de la televisión; TVE; reporterismo periodístico; periodismo de corresponsalía; reportero; reportaje.

\section{History of the Spanish reporter. Case study of Miguel de la Quadra-Salcedo under digital perspective}

\begin{abstract}
The reporter journalism in Spain has a profuse journalistic work and many professionals displaced to the places where the events rise up and are narrated. In a context of democratized, digital, ubiquitous, social and multi-screen broadcasting, it is necessary to approach the history of reporter journalism in our country, and know the work done to bring it into value. This article studies the figure of Miguel de la Quadra-Salcedo and the digitization of his journalistic work carried out by TVE. Also, is ascertained its presence in the main social networks and platforms before and after of his death.
\end{abstract}

Keywords: Television history; Spanish TV; reporter journalism; correspondent journalism; reporter; report.

\section{Referencia normalizada}

Segarra-Saavedra, J. y Páramo-Galdón, P. (2016). Historia del reporterismo español. Estudio de caso de Miguel de la Quadra-Salcedo bajo la perspectiva digital. Historia y Comunicación Social. Vol 21, número 2, páginas 513-525. 
Sumario: 1. El periodismo de reporterismo y corresponsalía en España. 2. Perspectiva cronológica de Miguel de la Quadra-Salcedo. 3. Planteamiento investigador, objetivos y metodología. 4. Resultados. 5. Conclusiones. 6. Referencias bibliográficas.

\section{El periodismo de reporterismo y corresponsalía en España}

Mientras que la RAE define al reportero como el periodista "que se dedica a los reportes o noticias", para el presente artículo se parte del reporterismo como el ejercicio que realiza el periodista desde el lugar en el que suceden los hechos. De esta forma, recopilar la información de primera mano, verificarla y difundirla sería la labor principal del reportero. Todo ello hecho desde la mayor objetividad posible, ya que la opinión y las valoraciones personales no tienen cabida en este tipo de periodismo, que ha sido investigado con anterioridad por Aguilera (1999) y Carrasco (2013) entre otros.

En España el reporterismo goza de una dilatada historia y tradición. Nombres como Miguel de la Quadra-Salcedo (1932-2016), Manolo Alcalá (1934-1991), Alberto Vázquez-Figueroa (1936-), Jesús González Green (1937-), Diego Carcedo (1940-), Manu Leguineche (1941-), Carmen Sarmiento (1944-) y Arturo Pérez Reverte (1951-) son sólo algunos de los más destacados y conocidos profesionales en este ámbito.

Ellos fueron los encargados de narrar en primera persona y acercarnos a través de su pluma o de la pequeña pantalla conflictos armados como la guerra de Vietnam (1955-1975) en el caso de Manu Leguineche; la guerra de Bosnia (1992-1995) en la figura de Pérez Reverte, o algunos de los golpes de estado en Argentina contados por Carmen Sarmiento. Sirvan estos ejemplos para resumir la importancia del trabajo de estos y otros profesionales gracias a los cuales los españoles pudimos conocer en su momento lo que sucedía fuera de nuestras fronteras, en un tiempo donde los periódicos, la radio y la televisión eran los únicos cauces posibles de información.

Hoy en día el contexto ha cambiado radicalmente. Ahora los medios de comunicación tradiciones han cedido terreno ante las redes sociales y cualquier individuo con un smartphone, una tablet o un ordenador portátil y acceso a internet puede convertirse en informador improvisado. Además, estos reporteros amateurs no sólo pueden contar en tiempo real lo que está sucediendo en cualquier lugar del mundo, sino que pueden -al mismo tiempo- distribuir por la red fotografias y vídeos que llegarán a millones de internautas en todo el planeta en apenas unos segundos.

Ante este panorama, cabría reflexionar hacia donde se dirige el reporterismo y hasta qué punto los medios de comunicación - más centrados a veces en sus cifras que en su labor de servicio público- utilizarán el concepto emergente del periodismo ciudadano (Pedreira, 2013; Martínez-Arias, 2015) como excusa para reducir el número de sus reporteros en plantilla. 


\section{Perspectiva cronológica de Miguel de la Quadra-Salcedo}

Miguel de la Quadra-Salcedo y Gayarre, según recoge Pérez y Franco (2001), nació el 30 de abril de 1932 en Madrid y con cuatro años su familia se trasladó a vivir a Pamplona, donde se crio. Por esta razón, siempre se ha definido como vasco-navarro. Estaba casado desde 1965 con Marisol de Asumendi y tenía tres hijos: Rodrigo, Sol e Íñigo. Falleció en Madrid el 20 de mayo de 2016 a los 84 años.

En lo que a su formación se refiere, estudió la carrera de perito agrícola, pero nunca ejerció como tal. Durante su trayectoria profesional cabe destacar dos perfiles bastante diferenciados: el deportivo y el periodístico. En su juventud destacó como atleta compitiendo al más alto nivel en las especialidades de lanzamiento de jabalina, martillo, peso y disco. Logró un total de nueve campeonatos de España en estas categorías - seis en disco, dos en peso y uno en martillo- y batió la plusmarca mundial en lanzamiento de jabalina, aunque al utilizar una técnica fuera del reglamento, esta marca nunca fue homologada. Formó parte de la sección de Atletismo del Real Madrid C.F. y participó en los Juegos Olímpicos de Roma de 1960. Fue dieciocho veces internacional absoluto y dos veces internacional universitario. Sin duda, una carrera deportiva que - tal y como apuntan Carreño (2011), Antón (2015), Calvo (2015) y Del Campo (2015) - fue el preludio de su gran labor aventurera.

En 1961 viajó hasta Colombia donde trabajó para el gobierno colombiano durante dos años como etnobotánico en la selva del río Amazonas. En 1963 volvió a España con un gran reportaje fotográfico sobre la naturaleza salvaje amazónica que le valió para ser contratado como reportero por Televisión Española (TVE). De esta forma daba comienzo una interesante y prolífica carrera periodística recogida por Vázquez (2011), Pulido (2013), Coca (2015), Corbillón (2015), Drake (2015), Fernández (2015) y González (2015) entre otros, y que le llevó a recorrer todo el mundo cubriendo informativamente acontecimientos de toda índole.

En 1963, durante la crisis de la República Democrática del Congo, realizó su primer trabajo periodístico informando y rodando el fusilamiento de 300 prisioneros, por lo que fue condenado a muerte, aunque la condena no llegó a ejecutarse. Después llegó el turno de la guerra de Vietnam y del golpe de Estado de Pinochet en Chile, en 1973.

Más allá de su periodismo de guerra, también fueron célebres sus entrevistas a relevantes personalidades de diferentes ámbitos, desde el Dalai Lama o Gandhi hasta Salvador Allende, Pablo Neruda o el hermano del Che Guevara entre muchos otros.

Presentó y protagonizó los programas A toda plana (TVE, 1965-1967); Aventura (TVE, 1969); Los reporteros (TVE, 1974-1976); El mundo en acción (TVE, 1978); Españoles en el Pacífico (TVE, 1980); A la caza del tesoro (TVE, 1984); Aventura 92 (TVE, 1988-1992) y Ruta Quetzal (1993-). También trabajó junto a Félix Rodríguez de la Fuente en el programa La Actualidad Española (TVE, 1957-1958).

Pero si por algo es realmente conocido y será recordado de la Quadra-Salcedo es por su gran proyecto: Ruta Quetzal. La iniciativa nació en 1979, cuando el Rey 
Don Juan Carlos propuso al reportero y aventurero la creación de un programa de intercambio de jóvenes de latinoamérica, España y Portugal. El proyecto vio la luz en 1985 bajo la denominación de Aventura 92, después recibió el citado nombre de Ruta Quetzal y desde hace un tiempo es denominado como Ruta BBVA, debido al patrocinio del banco que le da nombre.

El programa fue declarado de interés universal por la Unesco, y en el mismo han participado hasta la fecha más de 10.000 jóvenes. Cada año desde 1979, la iniciativa de De la Quadra reúne durante cuarenta y cinco días, en los meses de junio y julio, a chicos y chicas de 16 y 17 años para realizar un viaje a América Latina en el que los participantes desarrollan estudios geográficos, históricos y medioambientales.

Su prolífica trayectoria en el ámbito periodístico y en su faceta de aventurero le valieron múltiples reconocimientos en forma de premios y condecoraciones entre los que cabe destacar los siguientes:

- Encomienda de la Orden del Mérito Civil.

- Medalla al Mérito Agrícola.

- Premio Ondas (1973) nacional de Televisión.

- Antena de Oro (1968) por A toda plana.

- Antena de Oro Extraordinaria (2002).

- Premio ATV (2004) por su trayectoria profesional.

- Premio periodismo Pueblo por Tres años en el Amazonas.

- Premio Nacional de Televisión por Managua y el Terremoto.

- Premio Nacional de Televisión por Camaño y los marines.

- Premio Internacional de la crítica de Televisión en Cannes por La muerte del Che Guevara.

- Premio Internacional de Televisión por La larga marcha de los eritreos.

- Medalla de plata de la Real Orden del Mérito Deportivo.

- Orden de Antonio José de Irisarri (2006).

- Premio Ítaca a su trayectoria, otorgado por la Facultad de Ciencias de la Comunicación (UAB).

- Premio Turismo de Las Encartaciones, Vizcaya (2007).

- Gran Cruz de la Orden del Dos de Mayo, Madrid (2008).

- Premio Plus.es al personaje intergeneracional, Madrid (2010).

- Medalla de Extremadura, Mérida (2012).

Además, en dos ocasiones -2005 y 2009- la Asociación de Amigos de Miguel de la Quadra-Salcedo-AdAMIQUS- le ha propuesto como candidato para recibir el Premio Príncipe de Asturias de la Concordia.

En 2009 el Gobierno de Navarra le concedió la medalla de la Cruz de Carlos III El Noble de Navarra, como reconocimiento a su labor en el progreso de la Comunidad Foral y su proyección hacia el exterior.

Poco antes de su muerte, Miguel de la Quadra estaba retirado de la televisión aunque seguía participando, en la medida que su salud se lo permitía, en la organiza- 
ción de Ruta BBVA tal y como recoge Martínez-Fornés (2015). Porque un accidente de helicóptero en el que cayó al mar y el agua encharcó sus pulmones le apartó de viajar hasta América acompañando a los jóvenes aventureros. Sin embargo, siguió encabezando el proyecto desde España. Su última aparición pública fue el 28 de julio de 2015 cuando acudió a una recepción que el rey Felipe VI ofreció a los integrantes de la expedición de ese año.

\section{Planteamiento investigador, objetivos y metodología}

El presente estudio surge del interés del equipo investigador en conocer y profundizar en la obra periodística del reportero y corresponsal Miguel de la Quadra-Salcedo, estrechamente vinculado al programa de estudios y aventuras Ruta Quetzal o Ruta BBVA.

Entre los objetivos planteados en esta investigación destacan:

- Poner en valor el periodismo de reportero y la figura del reporterista.

- Rememorar la obra periodística del reportero y corresponsal Miguel de la Quadra-Salcedo y Gayarre.

- Conocer la vida y palmarés deportivo de uno de los representantes de España en los Juegos Olímpicos de Roma en 1960.

- Profundizar cronológicamente en aspectos desconocidos de su obra.

- Detectar la atención que ha recibido su labor periodística por parte de la comunidad científica en Dialnet, WOK-Scopus, Proquest y Google Scholar.

- Identificar y analizar su presencia en los principales contenidos online procedentes del archivo histórico digitalizado de RTVE.es.

- Rastrear sus posibles apariciones publicadas por los usuarios de internet en las principales plataformas y redes sociales: Wikipedia, Youtube, Facebook y Twitter.

- Así como identificar la repercusión de su fallecimiento en medios y redes sociales.

En definitiva, se trata de actualizar y poner en valor la obra de Miguel de la Quadra, tratando de detectar la literatura vertida sobre él para posteriormente analizar las principales entradas digitales referentes a su obra, todo ello contextualizado en plena era de las redes sociales, los perfiles profesionales, y las plataformas del conocimiento en línea y participativo.

Para ello se utilizan diversas técnicas de investigación como la búsqueda y revisión bibliográfica realizada el 10 de abril de 2016 en las bases de datos y repositorios Dialnet, Web of knowledge (WOK-Scopus), Proquest y Google Scholar; así como el rastreo por internet tanto en la web de Radio Televisión Española, como en Wikipedia, Youtube, Facebook y Twitter, en dos momentos diferentes: 10 de abril y 10 de junio de 2016. El estudio se completa con el análisis descriptivo tanto de las prin- 
cipales entradas en la hemeroteca de RTVE como de su presencia en la plataforma audiovisual Youtube, todas ellas ordenadas por criterios de relevancia.

\section{Resultados}

Por una parte, la búsqueda bibliográfica realizada en Dialnet identifica trece documentos que responden al concepto de búsqueda "Miguel de la Quadra-Salcedo". De todos ellos, la revisión bibliográfica permite destacar mayoritariamente las entrevistas realizadas con motivo de su participación en las distintas ediciones de la Ruta Quetzal; el libro Miguel de la Quadra Salcedo: el último explorador, escrito por Antonio Pérez Henares y publicado por Plaza y Janés en 2001, así como la entrevista publicada por la revista de la Academia de las Ciencias y las Artes de Televisión de España en 2013.

En cambio, las búsquedas realizadas en Web of knowledge (WOK-Scopus) y Proquest no han encontrado referencia alguna. De ahí que el estudio se haya completado con el rastreo en Google Scholar, donde con el mismo concepto de búsqueda se han encontrado hasta 535 resultados. Con el fin de filtrar las referencias encontradas, se han excluido las citas y las patentes, lo que ha permitido identificar siete obras principales alusivas al reportero en estudio. Si bien, el hecho de profundizar en su lectura permite considerar algunas de las entradas poco relevantes por lo que se desprende que Miguel de Quadra-Salcedo es una figura dentro del periodismo español que ha recibido escasa atención investigadora por parte de la comunidad científica. De ahí, además, la pertinencia del presente estudio.

Este resultado supone que el equipo investigador haya tenido que utilizar la literatura gris (Ayuso, 2004) y las entrevistas publicadas por numerosos medios y soportes informativos para profundizar en el estudio de la figura y la obra periodística de Miguel de la Quadra.

Por otra parte, el rastreo de la página web de Radio Televisión Española del 10 de abril ha permitido identificar las 25 principales entradas que responden al concepto de búsqueda coincidente con el nombre y apellidos de nuestro reportero objeto de estudio.

Su registro en una base de datos creada ex profeso junto al título, fecha de publicación en la web, clasificación del medio -radio o televisión- así como del tipo de contenido radiofónico o televisivo -entrevista, serie, crónica en informativo, documental, cabecera o programa- y su duración permite conocer los principales contenidos sonoros y audiovisuales que recoge el ente público donde se desarrolló gran parte de la carrera profesional de Miguel.

Así, atendiendo a la fecha de publicación en la web se detecta que el vídeo más antiguo data del 15 de diciembre de 1976. Concretamente es el primer capítulo del programa Mundo en acción (TVE, 1973-1978). En cambio, el más reciente a la fecha 
de estudio fue publicado el 7 de abril de 2016 y coincide con la presencia de Miguel en el avance del capítulo 304 "La rueda de recambio" de la serie televisiva Cuéntame cómo pasó (TVE, 2001).

De las 25 entradas, sólo el 8\% (2) pertenecen a Radio Nacional de España. El restante 92\% (23) están disponibles en la hemeroteca de Televisión Española.

Profundizando en su estudio, se detecta que el 40\% (10 entradas) son relativas a programas de televisión o secciones de programas, seguidos del $36 \%$ concernientes a las 9 entrevistas. Le sigue el 12\% (3) de documentales y el $4 \%$ (1) tanto de series como de crónicas en informativos y cabeceras de programas.

El estudio de la duración de las entradas permite conocer que el vídeo más largo es la crónica "El reportero que quisimos ser" recuperado en el año 2015, mientras que el más breve es el avance publicitario del capítulo de Cuéntame. Del estudio global se desprende que la duración media de las entradas radiofónicas y televisivas se sitúa en los 18'46".

Tabla 1. Principales entradas en la hemeroteca de RTVE.es referentes a Miguel

\begin{tabular}{|l|c|c|}
\hline Título & $\begin{array}{c}\text { Fecha } \\
\text { publicación }\end{array}$ & Duración \\
\hline $\begin{array}{l}\text { Las mañanas de RNE - Miguel de la Quadra Salcedo: “Para mí } \\
\text { la aventura es una ecuación de la vida” }\end{array}$ & $28 / 4 / 15$ & $05: 58$ \\
\hline América hoy - Miguel de la Quadra Salcedo, Ruta Quetzal & $12 / 2 / 15$ & $07: 22$ \\
\hline $\begin{array}{l}\text { Antonio y Carlos viajan a Córdoba y Cruz es acusado de ser el } \\
\text { violador del barrio }\end{array}$ & $5 / 4 / 16$ & $00: 13$ \\
\hline De la Quadra-Salcedo: El reportero que quisimos ser & $25 / 5 / 15$ & $57: 11$ \\
\hline $\begin{array}{l}\text { Reporteros de la historia de TVE (II) Miguel de la Quadra- } \\
\text { Salcedo: nómada por vocación }\end{array}$ & $5 / 11 / 09$ & $06: 07$ \\
\hline Mundo en acción & $26 / 1 / 77$ & $01: 27$ \\
\hline Sintonía de ‘Mundo en acción' & $21 / 6 / 11$ & $00: 53$ \\
\hline Mundo en acción - Marco Polo (capítulo 5) & $12 / 1 / 77$ & $02: 14$ \\
\hline Mundo en acción - Marco Polo (capítulo 6) & $19 / 1 / 77$ & $28: 22$ \\
\hline Quadra-Salcedo: ¿Por qué reportero y no funcionario? & $24 / 3 / 10$ & $01: 08$ \\
\hline Quadra-Salcedo: corresponsal de guerra & $24 / 3 / 10$ & $00: 45$ \\
\hline Quadra-Salcedo: la llamada de la selva & $24 / 3 / 10$ & $01: 47$ \\
\hline Quadra-Salcedo: su lugar preferido & $24 / 3 / 10$ & $00: 34$ \\
\hline Quadra-Salcedo: el reporterismo de ayer y el de hoy & $24 / 3 / 10$ & $01: 10$ \\
\hline Quadra-Salcedo: su entrevista más complicada & $24 / 3 / 10$ & $00: 29$ \\
\hline $\begin{array}{l}\text { Mundo en acción': Miguel de la Quadra nos acerca a los viajes } \\
\text { de Marco Polo }\end{array}$ & $19 / 5 / 10$ & $28: 16$ \\
\hline Mundo en acción - Marco Polo (capítulo 1) & $15 / 12 / 76$ & $28: 16$ \\
\hline
\end{tabular}




\begin{tabular}{|l|c|c|}
\hline Título & $\begin{array}{c}\text { Fecha } \\
\text { publicación }\end{array}$ & Duración \\
\hline Mundo en acción - Marco Polo (capítulo 2) & $22 / 12 / 76$ & $28: 11$ \\
\hline Mundo en acción - Marco Polo (capítulo 3) & $29 / 12 / 76$ & $28: 06$ \\
\hline Mundo en acción - Marco Polo (capítulo 4) & $9 / 1 / 77$ & $27: 45$ \\
\hline Mundo en acción - Marco Polo (capítulo 5) & $12 / 1 / 77$ & $27: 14$ \\
\hline Mundo en acción - Marco Polo (capítulo 6) & $19 / 1 / 77$ & $28: 22$ \\
\hline Aventura 92 - Primer programa & $3 / 8 / 89$ & $47: 00$ \\
\hline Ochéntame otra vez - Reporteros de guerra & $7 / 4 / 16$ & $53: 01$ \\
\hline Crónicas - De la Quadra-Salcedo: El reportero que quisimos ser & $4 / 6 / 15$ & $57: 15$ \\
\hline
\end{tabular}

Fuente: elaboración propia.

Este mismo estudio realizado después del fallecimiento del aventurero permite comprobar que tanto Televisión Española como Radio Nacional de España se hicieron eco de la noticia el mismo día que se conoció su muerte. Además, la web del ente publicó el 20 de mayo un recopilatorio en imágenes de toda su trayectoria.

Por otra parte, la información relativa a Miguel de la Quadra-Salcedo publicada en Wikipedia se divide en biografía, trayectoria en televisión, premios y condecoraciones, palmarés nacional e internacional como atleta y marcas personales. Su última actualización previa a su fallecimiento databa del 30 de diciembre de 2015 y desde entonces viene actualizándose con mayor asiduidad. Con abundantes datos, fechas y contenidos informativos y fotográficos, la entrada del reportero en la enciclopedia libre y colaborativa de la Fundación Wikimedia ocupa la primera posición en las búsquedas encontradas por Google.

A diferencia de lo ocurrido en las bases de datos científicas e investigadoras, la presencia de Miguel en Youtube es profusa y abundante. En la fecha de estudio -10 de abril de 2016- se encuentran hasta 3.240 entradas en la red social audiovisual de Google. Ordenadas por relevancia, el estudio aquí presentado se centra en analizar los primeros dieciocho vídeos ubicados en la primera página que ofrece Youtube tras su búsqueda. Las variables de estudio pasan por recoger y analizar sus títulos, usuarios, número de suscriptores, fecha de publicación y duración, así como el estudio cuantitativo de sus visualizaciones, Me Gusta, No Me Gusta, comentarios y comparticiones. 
Tabla 2. Principales entradas en Youtube referentes a Miguel

\begin{tabular}{|c|c|c|c|c|c|c|c|c|}
\hline Título & 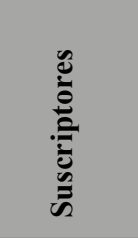 & 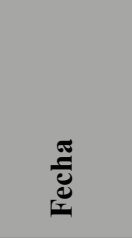 & 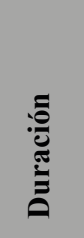 & 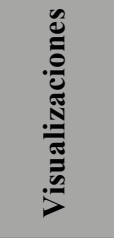 & 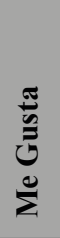 & 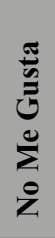 & 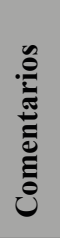 & 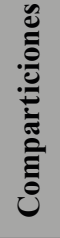 \\
\hline $\begin{array}{l}\text { Miguel De La Quadra- } \\
\text { Salcedo, pionero del } \\
\text { reporterismo }\end{array}$ & 99.744 & $30 / 6 / 15$ & $7: 31$ & 1.322 & 2 & 1 & 0 & 3 \\
\hline $\begin{array}{l}\text { Celebrities Miguel de la } \\
\text { Cuadra Salcedo Muchachada } \\
\text { Nui 3x06 } 2 \text { de } 6\end{array}$ & 2.066 & 24/3/09 & $5: 48$ & 251.615 & 564 & 19 & 110 & $\mathrm{X}$ \\
\hline $\begin{array}{l}\text { Miguel De La Quadra- } \\
\text { Salcedo, un atleta fuera de } \\
\text { serie }\end{array}$ & 99.744 & $30 / 6 / 15$ & $6: 43$ & 1.143 & 3 & 0 & 0 & 5 \\
\hline $\begin{array}{l}\text { Miguel de la Quadra-Salcedo } \\
\text { habla sobre la expedición } \\
2013 \text { - Ruta Quetzal BBVA }\end{array}$ & 3.735 & $22 / 5 / 13$ & $3: 23$ & 5.125 & 22 & 2 & 4 & 12 \\
\hline $\begin{array}{l}\text { Entrevista a Miguel de la } \\
\text { Quadra-Salcedo }\end{array}$ & 6 & $21 / 2 / 15$ & $3: 12$ & 541 & 4 & 0 & 0 & 6 \\
\hline $\begin{array}{l}\text { Muchachada nui } 3 \times 07 \\
\text { presentado por Miguel de la } \\
\text { Quadra-Salcedo }\end{array}$ & 14.988 & $2 / 4 / 09$ & $8: 48$ & 19.162 & 64 & 2 & 14 & $\mathrm{X}$ \\
\hline $\begin{array}{l}\text { Miguel de la Quadra Salcedo, } \\
\text { recordman mundial 'no } \\
\text { oficial' de jabalina }\end{array}$ & 2.108 & $14 / 11 / 12$ & $2: 12$ & 7.075 & 7 & 0 & 0 & $\mathrm{X}$ \\
\hline $\begin{array}{l}\text { Miguel De La Quadra- } \\
\text { Salcedo, emparentado con el } \\
\text { Cid campeador }\end{array}$ & 99.744 & $30 / 6 / 15$ & $7: 45$ & 998 & 10 & 0 & 1 & 4 \\
\hline $\begin{array}{l}\text { Golpe de Estado en Chile de } \\
1973 \text { y Muerte de Salvador } \\
\text { Allende - Miguel de la } \\
\text { Quadra-Salcedo }\end{array}$ & 2.501 & $2 / 6 / 15$ & $15: 27$ & 31.230 & 106 & 6 & 46 & 178 \\
\hline $\begin{array}{l}\text { Lanzamiento de jabalina en } \\
\text { Anoeta }\end{array}$ & 6 & $23 / 2 / 15$ & $1: 10$ & 959 & 2 & 0 & 0 & 9 \\
\hline $\begin{array}{l}\text { Miguel de la Quadra Salcedo } \\
\text { y su histórico programa } \\
\text { Aventura } 92\end{array}$ & 46 & $13 / 7 / 11$ & $9: 42$ & 2.827 & 6 & 1 & 3 & 7 \\
\hline $\begin{array}{l}\text { Adelanto Muchachada Nui- } \\
\text { Celebrities - Miguel de la } \\
\text { Quadra - Salcedo }\end{array}$ & 1499.064 & 24/3/09 & $1: 08$ & 18.719 & 17 & 1 & 7 & $\mathrm{X}$ \\
\hline $\begin{array}{l}\text { El carácter aventurero de De } \\
\text { La Quadra ha pasado a su } \\
\text { hijo y nieto }\end{array}$ & 99.744 & $30 / 6 / 15$ & $4: 40$ & 1.035 & 3 & 1 & 0 & 4 \\
\hline $\begin{array}{l}\text { Jabalina al estilo español } \\
(1956)\end{array}$ & 630 & $21 / 10 / 13$ & $1: 40$ & 51.392 & 60 & 1 & 2 & 145 \\
\hline
\end{tabular}




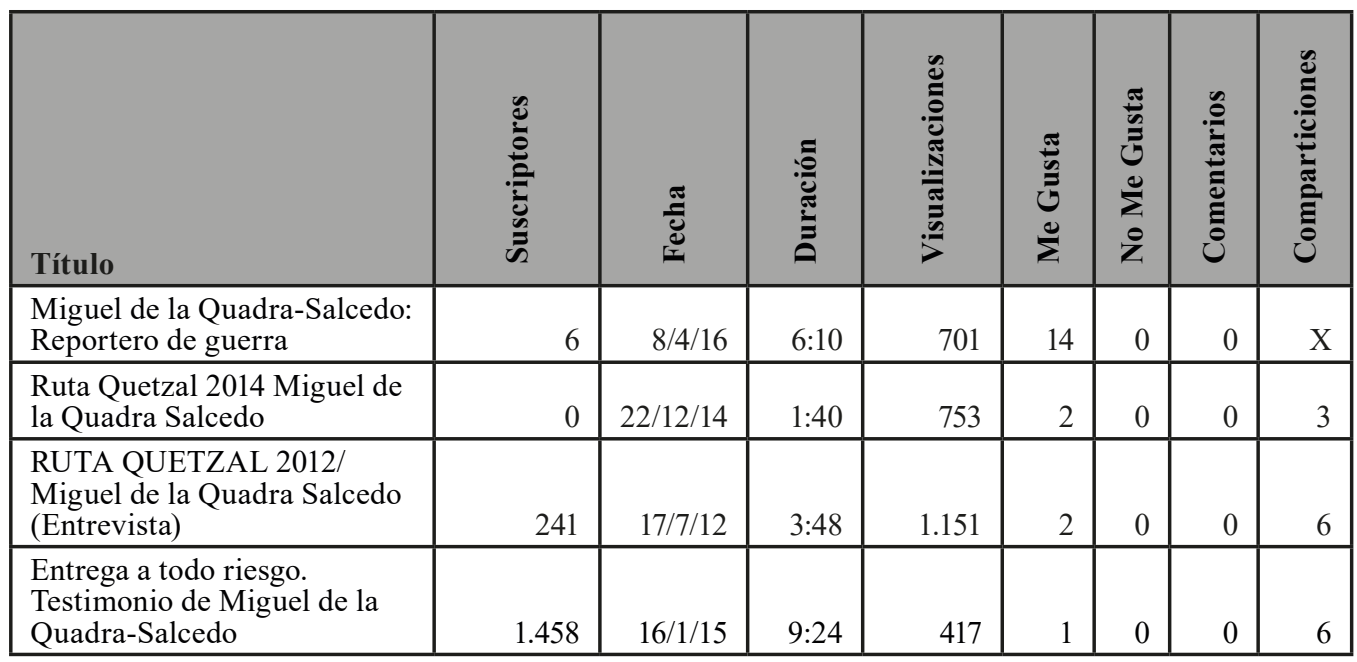

Fuente: elaboración propia.

De los resultados del estudio de Youtube se desprende que al menos cuatro vídeos están alojados en el canal de la cadena radio-televisiva vasca EITB. Otros usuarios que alojan contenidos en Youtube sobre Miguel son la organización de la Ruta Quetzal, su propio hijo Rodrigo y el canal de RTVE en Youtube, siendo este último el que mayor número de suscriptores posee -1.499.064- y el que menos el del vástago del reportero investigado.

Tomando como variable de análisis la fecha de publicación, se identifica en el vídeo "Adelanto Muchachada Nui- Celebrities - Miguel de la Quadra - Salcedo" en el más antiguo, mientras que el más reciente es "Miguel de la Quadra-Salcedo: Reportero de guerra" alojado por su propio hijo. Igualmente, el promedio de duración de los vídeos se ubica en los 6'53", en el vídeo "Golpe de Estado en Chile de 1973 y Muerte de Salvador Allende - Miguel de la Quadra-Salcedo" el vídeo más largo (15’27”) y en "Adelanto Muchachada Nui- Celebrities - Miguel de la Quadra - Salcedo" el más corto.

Además, el equipo investigador ha querido conocer el alcance de los vídeos. Así, ha detectado que el promedio de visualizaciones se sitúa en poco más de los veintidós mil (22.009), siendo el vídeo del canal EITB "Celebrities Miguel de la Cuadra Salcedo Muchachada Nui 3x06 2 de 6" el de mayor alcance (251.615), cifra muy por encima del promedio. Estos resultados contrastan con la escasa participación de los usuarios de internet a la hora de interactuar con los contenidos más allá de sus visualizaciones pues el promedio de Me Gusta se sitúa en 49, el de No Me Gusta en 2 , el de comentarios en 10 y el de comparticiones en 30 .

Tras su fallecimiento, Youtube ha recogido otras entradas adicionales que desplazan a parte de las anteriores. La primera de ellas es la del perfil de Extremadura TV 
que redifundió el programa Crónicas (TVE 2) que emitió el mismo día de su muerte. Otros vídeos emitidos ese mismo día son los pertenecientes a la Real Federación Española de Atletismo (RFEA) como reconocimiento a su carrera deportiva, la Ruta BBA como despedida emotiva a su fundador y las agencias de noticias Europa Press y Efe. Además, el vídeo del usuario Josep Paradera se cuela entre las primera posiciones de Youtube con un vídeo publicado 8 días después de su pérdida.

Por otra parte, si detenemos la mirada en el estudio de la presencia de Miguel de Quadra-Salcedo en Facebook identificamos que existe una fan page de este registrada como figura pública. Enlazada a la entrada de Wikipedia anteriormente descrita, la difusión de este periodista en Facebook alcanza a 4.548 fans el 10 de abril y sobrepasa los 5.100 el 10 de junio. El perfil alberga desde contenidos audiovisuales en Youtube, noticias publicadas en numerosos medios de comunicación, reportajes del ente público televisivo, así como repost que realizan entidades formativas sobre el proyecto estrella de Miguel, entre otros, además de cuantioso material fotográfico de las numerosas expediciones del madrileño. Además, la página permite a los usuarios, no sólo comentar las entradas aquí recogidas sino también valorar al personaje mediante post, además de invitar a otros amigos a seguir a este profesional del reporterismo en España. No obstante, la última publicación data del 29 de abril de 2016.

En cambio, la presencia de Miguel de la Quadra-Salcedo en la red social de los 140 caracteres, Twitter, se limita a una cuenta creada en junio de 2013 y que hasta la fecha tan sólo recoge 67 tweets, 131 seguidores y sigue únicamente la cuenta "Ruta BBVA". En cambio, esta última alcanza a 4.519 seguidores con 13,3 K de tweets eminentemente audiovisuales pues hasta la fecha ha publicado 4.208 fotos y vídeos. Este resultado contrasta con Piedra (2016) quien recoge que el día de su fallecimiento, Miguel de la Quadra-Salcedo se convirtió en trending topic en España.

\section{Conclusiones}

A pesar de la distancia temporal que ha separado la labor profesional de Miguel de Quadra-Salcedo de la aparición y proliferación de las herramientas digitales de la comunicación, su obra estará presente gracias a la digitalización llevada a cabo principalmente por Radio Televisión Española, pero también por la labor multiplicadora acometida por numerosos usuarios que contribuyen a mantener latente el espíritu de este aventurero español a través de Wikipedia, Youtube, Facebook y Twitter entre otras.

Estos hechos permiten conocer a la sociedad actual y futura no sólo sus aventuras y proyectos formativos internacionales, sino también descubrir la historia del reporterismo periodístico en España, así como rememorar hechos y acontecimientos históricos que dejaron su impronta en la historia universal. Al mismo tiempo, las nuevas generaciones podrán ver el espíritu aventurero y nómada de este periodista por vocación. 
Llama la atención la escasa atención investigadora ofrecida por la comunidad científica frente a las numerosas colaboraciones brindadas por Miguel de la Quadra-Salcedo a sus compañeros y colegas periodistas, pues a través de numerosas entrevistas - la gran mayoría digitalizadas- permiten al investigador -e ineludiblemente a las futuras generaciones de profesionales de la comunicación- conocer los inicios de Televisión Española, así como una etapa fundamental para el periodismo en nuestro país.

\section{Referencias bibliográficas}

AGUILERA PERELLÓ, O. (1999). Ofa Bezunartea, Mercedes del Hoyo y Florentino Martínez (1998): 21 lecciones de reporterismo. Estudios sobre el mensaje periodístico, 5, 1999, 219-222.

ANTÓN, A. (2015). De la Quadra-Salcedo: "El deporte se ha corrompido". Disponible en http://www.expansion.com/sociedad/2015/06/14/557dc890ca474110 438b4585.html [consultada el 25/04/2016]

AYUSO GARCÍA, M. D. (2004). La literatura gris en entornos digitales: estrategias de calidad y evaluación. Revista Interamericana de Bibliotecología, 27(2), 49-70.

CALVO, M. (2015). Miguel de la Quadra-Salcedo: El interminable viaje a Itaca. Disponible en http://www.rfea.es/web/noticias/desarrollo.asp?codigo=8624\#.VyAFW jEmGt8 [consultada el 23/04/2016]

CARRASCO, M. (2013). El suicidiario o cómo provocar la muerte del reporterismo de guerra en los medios españoles. Cuadernos de periodistas: revista de la Asociación de la Prensa de Madrid, 26, 8-16.

CARREÑO, F. (2011). Miguel de la Quadra, un genio incomprendido. Disponible en http://www.marca.com/2011/07/05/atletismo/1309856561.html [consultada el 23/04/2016]

COCA, C. (2015). "Dejaba la ropa en la jaula para que los leones se acostumbraran a mi olor". Disponible en http://www.lasprovincias.es/sociedad/201511/04/dejaba-ropa-jaula-para-20151104133032.html [consultada el 24/04/2016]

CORBILLÓN, A. (2015). Miguel de la Quadra: El aventurero impaciente. Disponible en http://www.diariosur.es/sociedad/201509/07/miguel-quadra-aventurero-impaciente-20150907213822.html [consultada el 23/04/2016]

DEL CAMPO, B. (2015). Miguel de la Quadra-Salcedo, 83 años "dando guerra". Disponible en http://www.abc.es/espana/20150729/abci-quadra-aventurero-vida-201507281750.html [consultada el 24/04/2016]

DRAKE, V. (2015). Miguel de la Quadra-Salcedo: “¡No me tomes el pelo! ¡Cómo voy a parecerme a Indiana Jones!”. Disponible en http:/www.finanzas.com/xl-semanal/ella-el/20150719/miguel-quadra-salcedo-tomes-8675.html [consultada el 24/04/2016]

FERNÁNDEZ, J. (2015). Miguel De la Quadra Salcedo: "El elixir de la eterna juventud es la curiosidad". Disponible en http://www.elperiodico.com/es/noticias/ 
gente-y-tv/miguel-quadra-salcedo-elixir-eterna-juventud-curiosidad-3826273 [consultada el 25/04/2016]

GONZÁLEZ VALERO, S. (2015). "Un ordenador no podrá nunca sustituir el olor de la Tierra húmeda tras la lluvia". Disponible en http://www.elmundo.es/ciencia/20 15/10/18/5617aalee2704e6c528b4627.html [consultada el 23/04/2016]

MARTÍNEZ-ARIAS, S. M. (2015). Periodismo ciudadano, en los límites de la profesión periodística. Estudios sobre el mensaje periodístico, 21(2), 109-118.

MARTÍNEZ-FORNÉS, A. (2015). Miguel de la Quadra, al Rey: "Me he escapado del hospital para venir a verle". Disponible en http://www.abc.es/casa-del-rey/ rey-felipe-vi/20150728/abci-quadra-salcedo-201507281253.html [consultada el 25/04/2016]

PEDREIRA SOUTO, E. (2013). Periodismo ciudadano: entre la profesionalidad y la participación. Comunicación y hombre: revista interdisciplinar de ciencias de la comunicación y humanidades, 9, 21-22.

PÉREZ HENARES, A. y FRANCO, A. (2001). Miguel de la Quadra Salcedo: el último explorador. Madrid: Plaza \& Janés.

PIEDRA, M. Á. (2016). Las reacciones de los políticos y famosos a la muerte de Miguel de la Quadra-Salcedo: "Nos hizo soñar a muchos niños porque palpitaba aventura, periodismo y vida". Disponible en http://www.yotele.es/sin-categoria/ las-reacciones-de-los-politicos-y-famosos-a-la-muerte-de-miguel-de-la-quadrasalcedo-nos-hizo-sonar-a-muchos-ninos-porque-palpitaba-aventura-periodismoy-vida_31150/ [consultada el 10/06/2016]

PULIDO, S. (2013). Miguel de la Quadra-Salcedo: "Los recuerdos son historia viva, como decía Âlvaro Mutis, están en mis cromosomas y viajan bajo mi piel". Academiatv: la revista de la Academia de las Ciencias y las Artes de Televisión, 132, 8-11. Disponible en https://issuu.com/academiatv/docs/academiatv_132/1? $=1279994 / 6005909$

VÁZQ̄UEZ, M. C. (2011). Miguel de la Quadra Salcedo, Aventurero. Disponible en http://www.vivirextremadura.es/miguel-de-la-quadra-salcedo-aventurero [Consultada el 24/04/2016] 